\title{
Flap Fixation Using Tissue Glue or Sutures Appears to Reduce Seroma Aspiration After Mastectomy for Breast Cancer
}

Citation for published version (APA):

van Bastelaar, J., Theunissen, L. L. B., Snoeijs, M. G. J., Beets, G. L., \& Vissers, Y. L. J. (2017). Flap Fixation Using Tissue Glue or Sutures Appears to Reduce Seroma Aspiration After Mastectomy for Breast Cancer. Clinical Breast Cancer, 17(4), 316-321. https://doi.org/10.1016/j.clbc.2017.01.005

Document status and date:

Published: 01/07/2017

DOI:

10.1016/j.clbc.2017.01.005

Document Version:

Publisher's PDF, also known as Version of record

Document license:

Taverne

Please check the document version of this publication:

- A submitted manuscript is the version of the article upon submission and before peer-review. There can be important differences between the submitted version and the official published version of record.

People interested in the research are advised to contact the author for the final version of the publication, or visit the DOI to the publisher's website.

- The final author version and the galley proof are versions of the publication after peer review.

- The final published version features the final layout of the paper including the volume, issue and page numbers.

Link to publication

\footnotetext{
General rights rights.

- You may freely distribute the URL identifying the publication in the public portal. please follow below link for the End User Agreement:

www.umlib.nl/taverne-license

Take down policy

If you believe that this document breaches copyright please contact us at:

repository@maastrichtuniversity.nl

providing details and we will investigate your claim.
}

Copyright and moral rights for the publications made accessible in the public portal are retained by the authors and/or other copyright owners and it is a condition of accessing publications that users recognise and abide by the legal requirements associated with these

- Users may download and print one copy of any publication from the public portal for the purpose of private study or research.

- You may not further distribute the material or use it for any profit-making activity or commercial gain

If the publication is distributed under the terms of Article 25fa of the Dutch Copyright Act, indicated by the "Taverne" license above, 


\title{
Flap Fixation Using Tissue Glue or Sutures Appears to Reduce Seroma Aspiration After Mastectomy for Breast Cancer
}

\author{
James van Bastelaar, ${ }^{1,2,3}$ Lotte L.B. Theunissen, ${ }^{1}$ Maarten G.J. Snoeijs, ${ }^{2}$ \\ Geerard L. Beets, ${ }^{4,5}$ Yvonne L.J. Vissers ${ }^{1,2,3}$
}

\begin{abstract}
Seroma formation and its sequelae cause complications and discomfort following mastectomy. In this retrospective study of 230 patients, patients underwent flap fixation after mastectomy using sutures or tissue glue. The results were compared to a group that had not been treated with flap fixation. The occurrence of seroma was significantly less in the group undergoing flap fixation with sutures. There were significantly fewer patients requiring seroma aspiration in both groups undergoing flap fixation.

Background: Up to $90 \%$ of patients undergoing breast cancer surgery suffer from seroma formation, which can cause discomfort and various complications after mastectomy. This retrospective observational cohort study aimed to elucidate whether flap fixation with fibrin sealant (ARTISS) tissue glue reduces seroma formation and seroma aspiration after mastectomy when compared with flap fixation using Vicryl sutures and when compared with a conventional wound closure technique. Methods: All patients undergoing mastectomy due to invasive breast cancer or ductal carcinoma in situ were eligible for inclusion. From May 2012 to March 2013, all patients undergoing mastectomy in 2 large breast cancer centers were treated using flap fixation with Vicryl sutures. From September 2013 to March 2014, all patients undergoing mastectomy were treated with flap fixation using ARTISS tissue glue. The data were retrospectively analyzed and compared with a "drain-only" group that was not treated with flap fixation (May 2011-March 2012). Results: A total of 230 women who underwent mastectomy were retrospectively analyzed in this trial; 88 patients were included in the drain-only group (DO), 92 patients were included in the flap fixation group using Vicryl sutures (FF-1), and 50 patients were included in the flap fixation group using ARTISS tissue glue (FF-2). There was significantly less seroma formation in the group after flap fixation using sutures $(P=.006)$. There were significantly fewer patients who required seroma aspiration in the FF-1 group $(P=.001)$ and the FF-2 group $(P=.001)$ after undergoing mastectomy and sentinel node biopsy or modified radical mastectomy. Conclusion: This study suggests that flap fixation after mastectomy using ARTISS tissue glue or sutures reduces postoperative seroma aspiration. As a result, flap fixation might lead to less patient discomfort. A randomized, prospective trial should be performed to verify these results.
\end{abstract}

Clinical Breast Cancer, Vol. 17, No. 4, 316-21 @ 2017 Elsevier Inc. All rights reserved.

Keywords: ARTISS, Breast surgery, Fluid drained, Serous fluid, Vicryl stitches

\section{Introduction}

Seroma formation is a common complication after breast cancer surgery. The reported incidence of seroma varies between $3 \%$ to more than $90 \%$ in patients undergoing breast cancer surgery.

${ }^{1}$ Department of Surgery, Orbis Medical Center, Sittard, the Netherlands

${ }^{2}$ Department of Surgery, Atrium Medical Center, Heerlen, the Netherlands

${ }^{3}$ Zuyderland Medical Center (the merger of Atrium Medical Center and Orbis Medical Center), Heerlan, the Netherlands

${ }^{4}$ Department of Surgery, Netherlands Cancer Institute, Amsterdam, the Netherlands

${ }^{5}$ GROW School for Oncology and Developmental Biology, University of Maastricht, Maastricht, the Netherlands
This wide range is mostly explained by a lack of consensus on the definition of seroma and by the detection method used. ${ }^{3}$ Seroma is often considered to be a surgical nuisance or a necessary evil after breast cancer surgery, which generally resolves within several weeks.

Submitted: Dec 19, 2016; Accepted: Jan 12, 2017; Epub: Jan 24, 2017

Address for correspondence: James van Bastelaar, MD, Zuyderland Medical Center, Henri Dunantstraat 5, 6419 PC Heerlen, the Netherlands

E-mail contact: j.vanbastelaar@zuyderland.nl 
However, it often causes discomfort and in some cases even complications, varying from delayed wound healing to infection and skin flap necrosis. ${ }^{1,4,5}$ In addition to this, patients may require more frequent outpatient clinic visits for seroma and wound care. ${ }^{5}$ Moreover, complications caused by infection and delayed wound healing might postpone the start of adjuvant therapy. ${ }^{6}$ It is believed that reducing the dead space can prevent the accumulation of seroma. Certain prospective trials indicate that flap anchoring and therefore dead space reduction could be beneficial. ${ }^{7,8}$ Drains have been demonstrated to be helpful and there also is evidence that flap fixation with sutures does reduce seroma formation. ${ }^{8,9}$ In a previously conducted retrospective study by our group, flap fixation using Vicryl (polyglactin 910) sutures seemed to be an effective surgical technique in reducing dead space and therefore seroma formation and seroma aspiration in patients undergoing mastectomy for invasive breast cancer. ${ }^{8}$

ARTISS tissue glue is a fibrin sealant containing human protein and human thrombin. ARTISS is used as tissue glue to adhere/seal subcutaneous tissue in plastic, reconstructive, and burn surgery, as a replacement or an adjunct to sutures or staples. In addition, ARTISS can function as an adjunct to hemostasis on subcutaneous tissue surfaces. The fibrin adhesion system initiates the last phase of physiological blood coagulation. ARTISS is sprayed onto the skin flaps and underlying muscle, leading to adhesive fixation of the skin flap on the pectoral muscle. ${ }^{10}$ ARTISS tissue glue is made of pooled human plasma. It contains $4 \mathrm{IU} / \mathrm{mL}$ thrombin leading to an extended clotting time compared with Tisseel VHSD containing 500 $\mathrm{IU} / \mathrm{mL}$ thrombin. The skin graft should be attached to the wound bed immediately after ARTISS has been applied. The surgeon has up to 60 seconds to manipulate and position the graft before polymerization. Foster et $\mathrm{al}^{11}$ showed that both the incidence and the extent of hematoma/seroma were significantly lower for ARTISStreated sites than for stapled sites. The reduction in hematoma and seroma is clinically significant because of the additional procedures that are required to deal with these complications in certain cases.

Unlike Tisseel, ARTISS tissue glue is made of pooled human plasma. Flap fixation using Fibrin Glue (Tisseel) was evaluated in a Cochrane review in 2013. ${ }^{3}$ The authors found no influence on the incidence of postoperative seroma formation, the mean volume of seroma, wound infections, complications, or the length of hospital stay after mastectomy for breast cancer. ${ }^{3}$ However, due to a broad heterogeneity of included articles in the Cochrane review (eg, population, type of surgery), it is difficult to extrapolate these results to our group of patients.

The aim of this study was to evaluate whether ARTISS tissue glue reduces seroma formation and its sequelae when compared with flap fixation using Vicryl sutures or when compared with conventional wound closure with a drain only after mastectomy.

\section{Materials and Methods}

This retrospective observational cohort study was conducted in the breast units of 2 large hospitals in the Netherlands (Atrium Medical Center, Heerlen, and Orbis Medical Center, Sittard). The hospitals' joint medical ethical committee granted approval (14-N-115) and informed consent was waived. All procedures performed in studies involving human participants were in accordance with the ethical standards of the institutional and/or national research committee and with the 1964 Helsinki declaration and its later amendments or comparable ethical standards.

Women undergoing mastectomy for invasive breast cancer or ductal carcinoma in situ (DCIS) with or without sentinel node biopsy and modified radical mastectomy were eligible for inclusion. Direct reconstruction and breast-conserving surgery were exclusion criteria. All patients received $2 \mathrm{~g}$ cefazolin preoperatively. Two methods of flap fixation were applied. The method of flap fixation used depended on the period in which patients underwent mastectomy. Flap fixation using sutures (FF-1) was applied between May 2012 and March 2013. Flap fixation using ARTISS tissue glue (FF-2) was used between September 2013 and March 2014. In both groups, a low-suction drain was left in situ. The flap fixation group using ARTISS (FF-2) was compared with the flap fixation group using sutures (FF-1) and a drain-only control group (DO) that was not treated using flap fixation (May 2011-March 2012). In the control group, only a low-suction drain was left in situ. Drains were removed if fluid production was less than $50 \mathrm{~mL} / 24$ hours. After 7 days, all drains were removed, irrespective of drain output. Surgery was performed by 5 surgeons, all specialized in breast cancer surgery. Patients visited the outpatient clinic 1 to 2 weeks after surgery. A surgeon followed up these visits after 3 months and 1 year postoperatively. Extra visits were planned as deemed necessary.

\section{Surgical Techniques}

In patients in the skin flap fixation group using Vicryl sutures, the skin flaps were sutured onto the pectoral muscle using polyfilament absorbable sutures (Vicryl 3.0). Vicryl sutures were placed at periodic intervals (every $3 \mathrm{~cm}$ ) in 2 or 3 rows, depending on the extent of the skin flaps. In the group using tissue glue, ARTISS was applied as a 2-mL spray and used on both skin flaps. After the spray was applied, compression on both skin flaps to the underlying muscle was applied for 3 minutes. Intradermal skin closure using absorbable monofilament sutures (Monocryl 3.0) was applied to patients in all groups.

\section{Outcome Assessment}

We evaluated patient characteristics of all participants using electronic medical records. Demographics of interest were as follows: age, smoking, body mass index, use of anticoagulants, and comorbidity. Seroma and seroma aspiration as well as other complications including wound infections were retrieved from the medical records. Infection was defined as any wound appearance that required antibiotic treatment or opening of the wound to evacuate infected seroma or abscess formation. Seroma was defined as a fluid collection as evidenced via palpation or clear serous fluid that was aspirated. Seroma aspirations were counted as registered in the patients' charts. Comorbidity was classified following the Charlson comorbidity index. ${ }^{12}$ All oral anticoagulants were considered to be anticoagulant drugs (ie, platelet aggregation inhibitors and warfarin). Tumor stage was classified according to TNM classification. ${ }^{13}$ The presence of seroma, seroma aspirations, and surgical site infections (SSI) were evaluated.

\section{Statistics}

Statistics were performed using SPSS, version 22 (IBM Corporation, Armonk, NY). Continuous variables are presented as 


\section{Flap Fixation Reduces Seroma Aspiration After Mastectomy}

\begin{tabular}{|c|c|c|c|c|c|}
\hline & $\begin{array}{l}\text { FF-2 (Glue) } \\
n=50\end{array}$ & $\begin{array}{c}\text { D0 (Drain Only) } \\
n=88\end{array}$ & $P$ (FF-2 vs. D0) & $\begin{array}{c}\text { FF-1 (Sutures) } \\
n=92\end{array}$ & $P$ (FF-2 vs. FF-1) \\
\hline Age $(y)$ & $62(13)$ & $69(11)$ & .001 & $67(13)$ & .04 \\
\hline Comorbidity & $3.8(2.2)$ & $3.0(1.1)$ & .02 & $2.8(1.4)$ & .007 \\
\hline Anticoagulant drugs (yes), \% & 38 & 34 & .65 & 25 & .11 \\
\hline Smoking (yes), \% & 10 & 24 & .04 & 23 & .07 \\
\hline Tumor stage, \% & & & .02 & & .03 \\
\hline $\mathrm{T} 1-2 \mathrm{NO}$ & 36 & 50 & & 44 & \\
\hline $\mathrm{T} 1-2 \mathrm{~N}+$ & 42 & 19 & & 25 & \\
\hline T3 & 10 & 9 & & 14 & \\
\hline T4 & 10 & 9 & & 3 & \\
\hline Ductal carcinoma in situ & 2 & 13 & & 13 & \\
\hline Operation, \% & & & .59 & & .56 \\
\hline $\begin{array}{l}\text { Modified radical } \\
\text { mastectomy }\end{array}$ & 42 & 36 & & 37 & \\
\hline Mastectomy & 10 & 16 & & 7 & \\
\hline Mastectomy sentinel node & 48 & 48 & & 57 & \\
\hline Blood loss, mL, \% & & & $<.001$ & & $<.001$ \\
\hline 0 & 12 & 37 & & 49 & \\
\hline $0-50$ & 48 & 17 & & 18 & \\
\hline $50-100$ & 24 & 14 & & 19 & \\
\hline $100-150$ & 8 & 2 & & 3 & \\
\hline$>150$ & 8 & 31 & & 12 & \\
\hline
\end{tabular}

means with SDs or as medians with first and third quartiles as appropriate; categorical variables are presented as percentages. Continuous variables were compared between study groups with Student's $t$-tests or Mann-Whitney $U$ tests as appropriate. Categorical variables were compared between study groups with $\chi^{2}$ tests or Fisher exact tests as appropriate. The risk of complications according to study group was estimated using simple logistic regression. Potential confounding by relevant baseline characteristics was corrected for using multiple logistic regression. The clinically relevant interaction between study group and operation type was assessed with the significance of the change in $-2 \log$ likelihood after inclusion of the interaction term in the logistic regression models. In case of significant interaction, simple effects were reported by stratified cross-tables. $P<.05$ was considered evidence of statistical significance.

\section{Results}

\section{Patient Demographics}

In total 230 patients were included; 92 in the flap fixation suture group (FF-1), 50 in the ARTISS group (FF-2), and 88 in the drainonly group (DO). Characteristics of the patients are summarized in Table 1. Women in the flap fixation suture group had significantly fewer comorbidities than in the ARTISS flap fixation group (2.8 vs. 3.8; $P=.007)$. Patients in the ARTISS group were significantly younger than patients in the other 2 groups (62 vs. 69; $P=.001$ ), 62 versus $67(P=.04)$. There were fewer smokers in the ARTISS group $(10 \%)$ when compared with the historical control group (24\%) $P=.04$. Besides these characteristics, operative features were compared among the 3 groups (eg, blood loss and type of surgery: modified radical mastectomy, mastectomy, or mastectomy with sentinel node biopsy). Some clear differences in blood loss emerged,

Table 2 Postoperative Complications

\begin{tabular}{|c|c|c|c|c|c|}
\hline & $\begin{array}{c}\text { FF-2 (Glue) } \\
n=50\end{array}$ & $\begin{array}{c}\text { D0 (Drain Only) } \\
n=88\end{array}$ & $\boldsymbol{P}$ & $\begin{array}{c}\text { FF-1 (Sutures) } \\
n=92\end{array}$ & $P$ \\
\hline Any complication, \% & 58 & 64 & .51 & 39 & .03 \\
\hline Seroma & 50 & 59 & .30 & 36 & .10 \\
\hline Seroma with aspiration & 14 & 43 & $<.001$ & 15 & .85 \\
\hline Number of aspirations & $0(0-0)$ & $0(0-1)$ & $<.001$ & $0(0-0)$ & .79 \\
\hline Hematoma & 6 & 1 & .14 & 5 & .89 \\
\hline Surgical site infection & 16 & 17 & .87 & 12 & .50 \\
\hline Pneumothorax & 0 & 1 & 1.00 & 0 & - \\
\hline
\end{tabular}


Table 3 Multiple Logistic Regression Analysis

\begin{tabular}{|c|c|c|c|c|}
\hline & \multicolumn{2}{|l|}{ Seroma } & \multicolumn{2}{|c|}{ Seroma Requiring Aspiration } \\
\hline & $\begin{array}{c}\text { Odds Ratio } \\
\text { (95\% Confidence Interval) }\end{array}$ & $\boldsymbol{P}$ & $\begin{array}{c}\text { Odds Ratio } \\
\text { (95\% Confidence Interval) }\end{array}$ & $P$ \\
\hline \multicolumn{5}{|l|}{ Closure technique } \\
\hline Drain only (reference) & - & - & - & - \\
\hline FF-2 (glue) & $0.83(0.38-1.80)$ & .64 & $0.19(0.07-0.52)$ & .001 \\
\hline FF-1 (sutures) & $0.41(0.22-0.78)$ & .006 & $0.29(0.14-0.61)$ & .001 \\
\hline Age (y) & $1.01(0.98-1.04)$ & .48 & $1.02(0.99-1.05)$ & .28 \\
\hline \multicolumn{5}{|l|}{ Operation } \\
\hline Mastectomy (reference) & - & - & - & - \\
\hline Mastectomy and sentinel node & $0.88(0.35-2.27)$ & .78 & $0.85(0.30-2.41)$ & .77 \\
\hline Modified radical mastectomy & $1.67(0.62-4.51)$ & .31 & $0.97(0.32-2.90)$ & .95 \\
\hline Comorbidity (point) & $0.93(0.74-1.16)$ & .51 & $1.18(0.91-1.55)$ & .22 \\
\hline Anticoagulant drugs (yes) & $1.00(0.50-1.97)$ & .99 & $1.10(0.50-2.43)$ & .81 \\
\hline Smoking (yes) & $1.85(0.90-3.78)$ & .09 & $0.78(0.34-1.79)$ & .55 \\
\hline
\end{tabular}

and are listed in Table 1 . There were no differences in the type of operation performed or the use of anticoagulants.

\section{Seroma and Complications}

Postoperative complications are listed in Table 2. There was a significant difference in overall complications between the ARTISS group (58\%) and the suture group (39\%), $P=.03$. Seroma aspiration was performed in $14(15.2 \%)$ of 92 in the suture group, in 7 $(14 \%)$ of 50 in the ARTISS group, and in $52(59.1 \%)$ of 88 in the DO group $(P<.001)$. Moreover, there were no significant differences in seroma aspiration between the flap fixation suture group and the flap fixation using ARTISS group $(P=.85)$. The number of seroma aspirations per patient who underwent seroma aspiration was also significantly reduced in both groups undergoing flap fixation (flap fixation with sutures and with ARTISS, $P<.001$ ). No significant differences were detected in patients developing SSIs in the 3 groups.

The multiple logistic regression analysis is shown in Table 3. When analyzing the effect of method of flap closure on seroma formation, there was significantly less seroma formation in the suture group (0.41 [0.22-0.78], $P=.006)$ when compared with the ARTISS group $(0.83[0.38-1.80], P=.64)$ and the historical control group (reference). Multivariate analysis clearly shows that flap fixation (both flap fixation with sutures and with ARTISS) is an independent variable significantly reducing seroma aspirations $(P<.001)$. Smokers did not have a higher risk of seroma formation after mastectomy $(P=.09)$.

The effect of wound closure method on seroma formation did not change significantly with operation type (test for interaction: $P=.15$ for seroma formation and $P=.54$ for seroma aspiration). Exploratory analyses stratified for operation type are presented in Table 4. No effect was seen in the group undergoing mastectomy ( $P=.21$ for seroma formation and $P=.42$ for seroma aspiration). In the group undergoing mastectomy and sentinel node biopsy, seroma formation was significantly reduced in the groups undergoing flap fixation (with sutures: 25\%, with ARTISS: 38\%, DO: $62 \%, P=.001)$. Moreover, seroma aspirations also were significantly reduced in both groups undergoing flap fixation in mastectomy and sentinel node biopsy (with sutures: 14\%, with ARTISS: $13 \%$, DO: $45 \%, P=.001$ ). In modified radical mastectomy, seroma aspiration also was significantly reduced in both groups undergoing flap fixation (with sutures: $18 \%$, with ARTISS: 14\%, DO: $41 \%, P=.04)$.

\section{Discussion}

This retrospective study indicates that flap fixation after mastectomy and sentinel node biopsy, using sutures or tissue glue, may reduce seroma formation. Seroma aspiration was significantly

Table 4 Effects of Flap Fixation on Seroma Formation Stratified by Operation Type

\begin{tabular}{l|c|c|c|c} 
& Do (Drain Only) & FF-1 (Sutures) & FF-2 (Glue) & \multicolumn{1}{|c}{} \\
Seroma, n/N (\%) & & & $3 / 5(60)$ & .21 \\
\hline Mastectomy & $8 / 14(57)$ & $1 / 6(17)$ & $9 / 24(38)$ & .001 \\
\hline Mastectomy and sentinel node & $26 / 42(62)$ & $13 / 52(25)$ & $13 / 21(62)$ & .89 \\
\hline Modified radical mastectomy & $18 / 32(56)$ & $19 / 34(56)$ & $1 / 5(20)$ & .42 \\
\hline Seroma requiring aspiration, n/N (\%) & $6 / 14(43)$ & $1 / 6(17)$ & $3 / 24(13)$ & .001 \\
\hline Mastectomy & $19 / 42(45)$ & $7 / 52(14)$ & $3 / 21(14)$ & .04 \\
\hline Mastectomy and sentinel node & $13 / 32(41)$ & $6 / 34(18)$ & & \\
\hline Modified radical mastectomy & & & \\
\hline
\end{tabular}




\section{Flap Fixation Reduces Seroma Aspiration After Mastectomy}

reduced in patients undergoing flap fixation using sutures (odds ratio [OR] 0.29 [0.14-0.61], $P=.001)$ and in patients undergoing flap fixation using tissue glue (OR 0.19 [0.07-0.52], $P=.001$ ). Moreover, seroma aspiration was significantly reduced in patients undergoing flap fixation after mastectomy and sentinel node or modified radical mastectomy.

Seroma formation remains a common complication after breast cancer surgery, with an incidence of up to $90 \% .{ }^{14}$ Unfortunately, no means of preventing seroma are known yet. Closed suction drainage has been pivotal in the prevention of seroma, but as all surgeons know, the problem and sequelae of seroma formation still persist. Various studies have shown that flap fixation using sutures is effective in combatting seroma. ${ }^{8,9}$ This is the first study to assess the effectiveness of ARTISS tissue glue in combatting seroma formation.

Flap fixation after mastectomy can be of great benefit in reducing seroma production and the number of seroma-related complications. ${ }^{8}$ Flap fixation using sutures and tissue glue appears to be beneficial, as the dead space between the skin flaps and underlying pectoral muscle is reduced. Furthermore, flap fixation does not seem to influence shoulder function and/or range of motion. ${ }^{9}$ Our study further indicates that seroma aspiration does not differ between the 2 methods of flap fixation.

When analyzing the interaction of operation type and method of wound closure, no significant effect was seen in seroma formation (flap fixation using sutures [17\%], flap fixation using ARTISS [60\%], DO [57\%], $P=.21$ ). Likewise, there were no significant differences in seroma aspiration in the group undergoing mastectomy alone (flap fixation using sutures [17\%], flap fixation using ARTISS [20\%], DO [43\%] seroma formation, $P=.42$ ). The low number of patients in this subgroup could explain the nonsignificance. If this group had been larger $(\mathrm{n}=$ 25), the difference possibly might have been statistically significant.

Gonzalez et $\mathrm{al}^{15}$ concluded that the incidence of seroma is highest after modified radical mastectomy. ${ }^{16}$ Our study revealed similar results; mastectomy without lymph node dissection yields fewer cases of seroma formation when compared with modified radical mastectomy or mastectomy without (sentinel) lymph node dissection. This could possibly be explained by the fact that the remaining dead space in the axilla persists, as dead space reduction remains difficult in the axilla due to the residual 3-dimensional space in the axilla. Unfortunately, no means of preventing seroma are known yet. However, many techniques in an attempt to reduce seroma formation have been investigated, but with little avail.

\section{Limitations}

The main limitation of this study is its retrospective nature. Indications for seroma aspiration had not been defined beforehand, and this could be considered as an information bias. In this study, the method of flap fixations was performed sequentially. Flap fixation using sutures was performed between May 2012 and March 2013, flap fixation using ARTISS was performed between September 2013 and March 2014. For that reason, it might be plausible that surgeons were more focused on establishing the presence of seroma in the latter part of the study. The presence of seroma in the historical control group could therefore be underestimated. As no objective test is used to diagnose seroma, its presence is subject to bias. Possibly, the only true measure of seroma formation is actual seroma aspiration.

\section{Conclusion}

In conclusion, flap fixation using ARTISS tissue glue seems to yield similar results when compared with flap fixation using sutures. Flap fixation using ARTISS tissue glue appears to lead to significantly fewer seroma aspirations in patients undergoing mastectomy and sentinel node biopsy and modified radical mastectomy for invasive breast cancer or DCIS when compared with patients without flap fixation. A prospective randomized controlled trial has been started (Seroma reduction $A$ fter Mastectomy Trial) to evaluate the effects of flap fixation (no flap fixation vs. flap fixation using sutures vs. flap fixation using tissue glue), including long-term outcome measures, such as cosmesis, shoulder function, patient satisfaction, quality of life, and cost-effectiveness.

\section{Clinical Practice Points}

- Seroma formation following mastectomy is very common and causes patient discomfort and complications.

- This study shows that flap fixation using ARTISS tissue glue appears to lead to significantly fewer seroma aspirations in patients undergoing mastectomy and sentinel node biopsy and modified radical mastectomy for invasive breast cancer or DCIS when compared with patients without flap fixation.

- There do not appear to be significant differences in seroma aspiration between the flap fixation suture group and the flap fixation group using ARTISS.

- This study formed the solid grounding of the SAM Trial, the first RCT of its kind that will evaluate the effects of flap fixation.

\section{Disclosure}

The authors have stated that they have no conflicts of interest.

\section{References}

1. Carless PA, Henry DA. Systematic review and meta-analysis of the use of fibrin sealant to prevent seroma formation after breast cancer surgery. Br J Surg 2006; 93:810-9.

2. Kumar S, Lal B, Misra MC. Post-mastectomy seroma: a new look into the aetiology of an old problem. J $R$ Coll Surg Edinb 1995; 40:292-4.

3. Sajid MS, Hutson KH, Rapisarda IF, Bonomi R. Fibrin glue instillation under skin flaps to prevent seroma-related morbidity following breast and axillary surgery. Cochrane Database Syst Rev 2013; 5:CD009557.

4. Stehbens WE. Postmastectomy serous drainage and seroma: probable pathogenesis and prevention. ANZ J Surg 2003; 73:877-80.

5. Kuroi K, Shimozuma K, Taguchi T, et al. Evidence-based risk factors for seroma formation in breast surgery. Jpn J Clin Oncol 2006; 36:197-206.

6. Khater A, Elnahas W, Roshdy S, et al. Evaluation of the quilting technique for reduction of postmastectomy seroma: a randomized controlled study. Int J Breast Cancer 2015; 2015:287398.

7. Almond LM, Khodaverdi L, Kumar B, Coveney EC. Flap anchoring following primary breast cancer surgery facilitates early hospital discharge and reduces costs. Breast Care (Basel) 2010; 5:97-101.

8. van Bastelaar J, Beckers A, Snoeijs M, Beets G, Vissers Y. Flap fixation reduces seroma in patients undergoing mastectomy: a significant implication for clinical practice. World J Surg Oncol 2016; 14:66.

9. Sakkary MA. The value of mastectomy flap fixation in reducing fluid drainage and seroma formation in breast cancer patients. World J Surg Oncol 2012; 10:8.

10. Inc. BI.ARTISS [Fibrin Sealant Human]. Deerfield: Baxter Healthcare Corporation; 2011. 
11. Foster K, Greenhalgh D, Gamelli RL, et al. Efficacy and safety of a fibrin sealant for adherence of autologous skin grafts to burn wounds: results of a phase 3 clinical study. J Burn Care Res 2008; 29:293-303.

12. Charlson M, Szatrowski TP, Peterson J, Gold J. Validation of a combined comorbidity index. J Clin Epidemiol 1994; 47:1245-51.

13. Sobin LH. TNM, sixth edition: new developments in general concepts and rules. Semin Surg Oncol 2003; 21:19-22.
14. van Bemmel AJ, van de Velde CJ, Schmitz RF, Liefers GJ. Prevention of seroma formation after axillary dissection in breast cancer: a systematic review. Eur J Surg Oncol 2011; 37:829-35.

15. Gonzalez EA, Saltzstein EC, Riedner CS, Nelson BK. Seroma formation following breast cancer surgery. Breast J 2003; 9:385-8.

16. Hashemi E, Kaviani A, Najafi M, Ebrahimi M, Hooshmand H, Montazeri A Seroma formation after surgery for breast cancer. World J Surg Oncol 2004; 2:44. 